\title{
LETTERS
}

\section{Mandatory reporting of professional incompetence}

James A Dunbar and Prasuna Reddy

To THE EDITOR: Arnold is correct to question whether the New South Wales reportable misconduct legislation will be effective, ${ }^{1}$ because it relies on doctors making a judgement about whether a colleague has flagrantly departed from accepted standards of professional practice. Doctors have a high threshold for referring to medical boards, in part because they perceive the system to be adversarial rather than recognising that individual and system factors can combine to create poor professional performance. Also, medical boards have no direct ability to modify the workplace circumstances to make them more supportive of a poorly performing doctor.

Poor performance has multiple causes, including mental and physical illness, cognitive impairment, substance misuse, professional isolation, and personality disorders. ${ }^{2}$ Flagrantly poor performance is rare, but research shows that the prevalence of poor performance is about one in a hundred doctors per annum. ${ }^{2}$ Many of these doctors are amenable to local remediation, provided there are properly promulgated procedures.
The United Kingdom and some states in the United States have developed systems for assessing poorly performing doctors that require directors of medical services to manage complaints locally. In the UK, the National Clinical Assessment Service is available to support medical directors in more complicated cases. Consequently, the number of referrals to the General Medical Council has decreased, but the number of doctors being reviewed has increased to the number that would be expected from research. ${ }^{3}$ Doctors reviewed by medical boards in Australia do not reach the predicted prevalence levels, and boards' processes seem slow by comparison with what can be done locally.

It is a moot point whether Dr Jayant Patel would have been reported under the new NSW legislation, because some of his colleagues appeared not to have thought that he flagrantly departed from accepted standards. The real problems in Bundaberg were that there were no local mechanisms for health professionals to raise their concerns. For almost 2 years, the director of medical services at the hospital took no direct action. ${ }^{4}$ Queensland Health is developing local processes that will be administered by directors of medical services supported by a clinical performance support service. ${ }^{5}$

The evidence against relying solely on medical boards and in favour of local procedures for managing poorly performing doctors is now incontrovertible. Currently, many poorly performing doctors are not being identified and offered remediation, and patients are being left at risk. These are important issues for the National Health and Hospitals Reform Commission.

James A Dunbar, Director

Prasuna Reddy, Director, Health Services

Research

Greater Green Triangle University Department of Rural Health, Flinders and Deakin

Universities, Warrnambool, VIC.

Director@greaterhealth.org

1 Arnold PC. Mandatory reporting of professional incompetence [editorial]. Med J Aust 2008; 189: 132-133.

2 Leape LL, Fromson JA. Problem doctors: is there a system-level solution? Ann Intern Med 2006; 144: 107-115.

3 National Clinical Assessment Service. Analysis of the first four years of referral data. http:// www.ncas.npsa.nhs.uk/resources/publications/keypublications/ (accessed Dec 2008)

4 Dunbar JA, Reddy P, Beresford B, et al. In the wake of hospital inquiries: impact on staff and safety. Med J Aust 2007; 186: 80-83.

5 Queensland Health. Safe doctors: fair system. http:// www.health.qld.gov.au/patientsafety/documents/ safdocsguide.pdf (accessed Aug 2008). 
Peter C Arnold

IN REPLY: The opinion expressed by Dunbar and Reddy that: "The real problems in Bundaberg were that there were no local mechanisms for health professionals to raise their concerns" ignores the many real difficulties (canvassed in my editorial $)^{1}$ confronting any member of staff who tried to raise their concerns within that institution. Local mechanisms cannot play their part if the institution's senior staff do not wish to implement them.

The ability of and, indeed, encouragement for all staff, regardless of seniority, to report their concerns directly to the medical board, bypasses all local deterrents. Our medical boards have the experience needed to sort out the major from the trivial, the genuine from the frivolous, incompetence from impairment.

Dunbar and Reddy continue: "The evidence against relying solely on medical boards and in favour of local procedures for managing poorly performing doctors is now incontrovertible." This is a straw man. No one, to my knowledge, has made any such suggestion.

What I support is: (i) a direct avenue for someone local to report to the medical board; (ii) diligent and sensitive enquiry by the medical board; and (iii) if needed, the cooperative implementation of remediation by the local entity and the medical board.

Peter C Arnold, Former Deputy President, NSW Medical Board

Sydney, NSW.

parnold@ozemail.com.au

1 Arnold PC. Mandatory reporting of professional incompetence [editorial]. Med J Aust 2008; 189: 132-133. 